
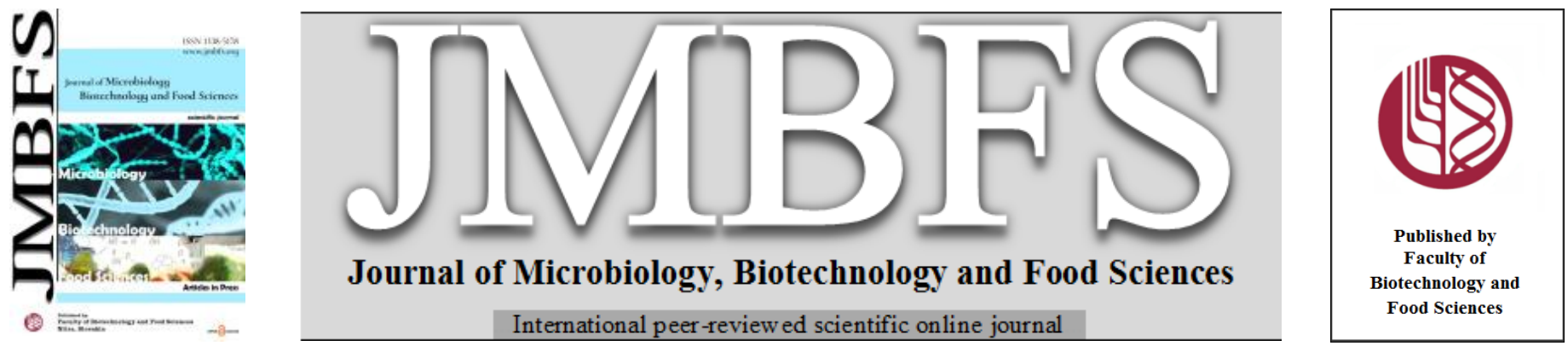

\title{
PREPARATION, OPTIMIZATION, CHARACTERIZATION AND ANTIMICROBIAL ACTIVITY OF CHITOSAN AND CALCIUM NANOPARTICLES LOADED WITH STREPTOMYCES RIMOSUS EXTRACTED COMPOUNDS AS DRUG DELIVERY SYSTEMS
}

\author{
Mohammed Nagib A. Hasaneen ${ }^{1}$, Mohamed. I. Abou-Dobara ${ }^{2}$ Samah M. Nabih' ${ }^{2}$ and Mohamed M. A. Mousa ${ }^{* 2}$
}

Address(es):

${ }^{1}$ Department of Botany, Faculty of Science, Mansoura University, Egypt.

${ }^{2}$ Department of Botany and Microbiology, Faculty of Science, Damietta University, New Damietta, Egypt.

*Corresponding author: mousa1451967@gmail.com

https://doi.org/10.55251/jmbfs.5020

\section{ARTICLE INFO}

Received 12.7. 2021

Revised 20.1.2022

Accepted 21. 1.2022

Published 1. 6. 2022

Regular article OPEN $\partial_{\text {ACCESS }}$

\begin{abstract}
The present study aims to search for a nano-delivery system that enables access of antimicrobial compounds to the targeting site of the microbial pathogens. To achieve this objective, the antimicrobial compounds extracted from the local isolate Streptomyces rimosus were loaded on chitosan (CS) and calcium phosphate (CaP) nanoparticles (NPs) to facilitate drug delivery to some species of bacteria (Escherichia coli ATCC25922, Staphylococcus aureus ATCC25923 and Bacillus cereus ATCC6633) and the yeast Candida albicans ATCC10231. The best incubation period for the production of antifungal and antibacterial compounds, $\mathrm{pH}$, temperature, carbon sources and nitrogen sources were around the third day, $7.0,30^{\circ} \mathrm{C}$, starch and potassium nitrate, respectively. The extracted compounds were identified using gas chromatography-mass spectrometry (GC-MS) analysis which revealed to the identification of nine antimicrobial organic acids. The prepared NPs were characterized using transmission electron microscopy (TEM) and Zeta potential analyser. Results showed those chitosan nanoparticles (CSNPs) were spherical shaped NPs with an average size $\approx 22 \pm 2 \mathrm{~nm}$. The CSNPs loaded with the antimicrobial molecule's diameter was ranged from 55 upto $100 \mathrm{~nm}$. Calcium phosphates nanoparticles (CaPNPs) were also spherical shaped NPs with diameter range from 70 to $95 \mathrm{~nm}$. Loading of antimicrobial compounds onto CaPNPs made them appeared in rod shape with width varying from 14 to $27 \mathrm{~nm}$ and length from 274 to $397 \mathrm{~nm}$. The synthesized NPs showed negative values confirming their high dispersity and long-term stability. The tested strains were resistant to solo NPs; but the loaded NPs with the extracted antimicrobial compounds, particularly the CaPNPs, augmented the potency of the isolated antimicrobial compounds, with emergence of differential antimicrobial activity. The activity of the NPs-bound antimicrobial compounds was more evident against bacteria than fungi, Grampositive bacteria than Gram-negative bacteria and against B. cereus than $S$. aureus.
\end{abstract}

\section{INTRODUCTION}

Microbial diseases are increasing yearly which represents an enormous challenge to human health, especially the improvement of antibiotic resistant strains in pathogenic microbes that considered as an alarming issue worldwide (Meade et al., 2021). It is well- established that the current medicinal regime delivers drugs to the site of action or inflammation with inescapable side effects (Malgorzata et al., 2020). Nanotechnology provides an efficient mean of sustained drug delivery and release with avoidance of the draw backs of the current delivery systems. For proper manipulation, medicaments must have a size such that they can be injected without occluding needles and capillaries (Hughes, 2005), and this task can be achieved by using either nano-liposomes, nano-gels, or micelles. By manipulating nanotechnology, drugs can be either loaded on the surface of nanoparticles (NPs) or encapsulated and carried within them to the drug destination. By this way, the effective drug dose can be lowered several orders of magnitude, which permits minimization of the drug side effects (Campagnolo et al., 2013). Chitosan (CS) is a safe natural biopolymer synthesized by basic de-acetylation of $\mathrm{N}$-acetyl glucosamine polymer (chitin) gotten from polymer, chitin, chitosan has drawn in critical consideration as an expected possibility for drug delivery because of its low poisonousness, biocompatibility and great biodegradability (Babii et al., 2020). Cs and its derivatives, bulk, or NPs have attracted considerable attention owing to its antimicrobial activity (Tsai and Su, 1999; Baka et al., 2020). The safe CS can interact with anions forming gels and complexes (Agnihotri et al., 2004; Kim and Rajapakse, 2005). CS hydrophilic property can simply cross-interface with counter anions to manage the drugs release (Hu et al., 2002). CS is a hydrophilic with mucoadhesion property (Janes et al., 2001), permeation enhancing properties (Dudhani \& Kosaraju, 2010) which ease the epithelial tight junctions opening (Yamamoto et al., 2005).
Calcium phosphates $(\mathrm{CaP})$ are the most important mineral component of human bone and teeth as well as the biological hard tissues in the form of carbonated hydroxyapatite, which afford stability, hardness, and proper function (Dorozhkin and Epple, 2002; Epple and Baeuerlein, 2007)

Synthetic $\mathrm{CaP}$ showed high biodegradability and biocompatibility and it had wide use in bioimaging, nanotechnology, medicine and tissue culture (Bakan et al., 2021). In addition, $\mathrm{CaPs}$ might equipped for separating into particles inside the cells and this property makes them fitting specialists for intracellular vehicle of the therapeutic genes and molecules (Bakan, 2018).

Calcium phosphates nanoparticles (CaPNPs) were manipulated as successful adjuvant with DNA vaccines (Joyappa et al., 2009). As the correspondence between the solubility of the carrier is inevitable and the antibiotic elution rate, CaPNPs is predictable to reveal slow-release performance (Wu et al., 2020). Since CaPNPs has high chemical stability, it limits some of its conceivable applications. Thus, soluble $\mathrm{CaP}$ could be benefited once more rapidly biodegradation achieved (Khalifehzadeh \& Arami, 2020). Goldschmidt et al. (2021) stated the antimicrobial action of $\mathrm{CaP}$ against $S$. aureus. Beigoli et al. (2021) demonstrated the antibacterial action of CaPNPs against S. mutans and E. Faecalis. He described its mode of action involving microbial DNA damage and enzymes deactivation. This action differs attributed to the species of bacteria and its structure. CaPNPs could adhered to the surface bacterial negatively charged molecules that harm the bacterial cell membrane leading to misfunction in its permeability, and finally give rise to cell death (Kadian et al., 2020). Antibiotic-resistant bacteria requires an improvement of new therapeutic methodologies to conquer the shortcoming of traditional antibiotics (Cano et al., 2020). Therefore, the present work focuses on the development and combination of chitosan nanoparticles (CSNPs) and CaPNPs with potent antimicrobial compounds that can aid in delivery of antibiotics to the target sites of drug-resistant microorganisms. 


\section{MATERIAL AND METHODS}

\section{Chemicals}

Chemicals were obtained from Oxoid (Oxoid Ltd., England). Microbial culture media was obtained from Difco Laboratories (Detroit, MI). Fluconazole (Diflucan) and Penicillin G (Pfizerpen) were obtained from Pfizer Corp, New York NY.

\section{Microorganisms}

The Streptomyces rimosus strain was isolated from the soil (Damietta, Egypt) and identified classically according to the Bergey's Manual of Systematic Bacteriology (Goodfellow et al., 2012). The bacterial and fungal strains used for the antimicrobial activity tests (Staphylococcus aureus ATCC25923, Bacillus cereus ATCC6633, Escherichia coli ATCC25922 and Candida albicans ATCC10231) were obtained from Damietta University (The collection culture of Microbiology lab, Faculty of Science).

\section{Experimental procedure}

\section{Optimization of the growth factors of the tested isolates}

Different environmental factors were tested such as specific incubation times intervals $(3,5,7$ and 9 days), different $\mathrm{pH}(4.0,5.0,6.0,7.0,8.0,9.0$ and 10.0), different temperature $\left(20,25,30\right.$ and $\left.37^{\circ} \mathrm{C}\right)$ and different carbon sources (starch glucose, glycerol, sucrose, lactose, chitin and cellulose; $20 \mathrm{gm} / \mathrm{l}$ ) and equimolecular weights from nitrogen sources (potassium nitrate; $\mathrm{KNO}_{3}(2.0 \mathrm{gm} / \mathrm{l})$, ammonium sulphate; $\left(\mathrm{NH}_{4}\right)_{2} \mathrm{SO}_{4}(1.96 \mathrm{gm} / \mathrm{l})$, sodium nitrate; $\mathrm{NaNO}_{3}(2.5 \mathrm{gm} / \mathrm{l})$ peptone $(2.9 \mathrm{gm} / 1)$, casein $(2.58 \mathrm{gm} / \mathrm{l})$, beef and yeast extract $(2.9 \mathrm{gm} / \mathrm{l})$. The antimicrobial potential of $S$. rimosus crude metabolite was tested against Gramnegative, Gram-positive bacteria and yeast. The best environmental conditions were determined according to the best inhibition zones (mm) (Gräfe et al., 1982).

\section{Extraction of antimicrobial compounds}

The antimicrobial compounds were extracted from the crude metabolites of $S$ rimosus using equal volume ratio (1:1) of different solvents successively (diethyl ether, petroleum ether, chloroform, and butanol). Each organic phase was separated individually and then evaporated with rotary evaporator. The resulting residue of each extraction ( $3 \mathrm{mg}$ ) was dissolved in $50 \mu \mathrm{L}$ of dimethyl sulphoxide (DMSO) for further antimicrobial activity tests.

The best solvent for the extraction of antimicrobial compounds was tested using mixing the filtrate with solvents (1:1) gradually and then separated using separating funnel equal. Small, concentrated discs $(5 \mathrm{~mm})$ of the extracted compounds were prepared and put on the surface of nutrient agar medium which inoculated with 0.5 McFarland standard $\left(1-2 \times 10^{8} \mathrm{CFU} / \mathrm{ml}\right)$ of pathogenic microbes. Inhibition zones were measured in mm (Nandhini et al., 2018).

\section{Gas chromatography mass spectroscopy analysis}

The sample chemical composition was achieved according to Hamed et al. (2019) method. Trace GC1310-ISQ mass spectrometer (Thermo Scientific, Austin, TX USA) and TG-5MS capillary column ( $30 \mathrm{~m} \times 0.25 \mathrm{~mm} \times 0.25 \mu \mathrm{m}$ film thickness) were used. The dissolvable postponement was $3 \mathrm{~min}$ and $1 \mu \mathrm{l}$ of test was infused consequently utilizing autosampler AS1300 combined with gas chromatography (GC) in the split mode. Electron ionization (EI) mass spectra were gathered at 70 $\mathrm{eV}$ ionization voltages over the scope of $\mathrm{m} / \mathrm{z} 40-1000$ in full output mode. The parts were distinguished by correlation of their maintenance times and mass spectra with those of WILEY 09 and NIST 11 mass spectral database (Shackleton and Marcos, 2006; Shackleton, 2008; Joel and Bhimba, 2012)

\section{Test for the minimal inhibitory concentration}

The microbiological test was done to determine the minimum inhibitory concentration (MIC) of the tested antimicrobial extracts against selected pathogenic strains (Clinical Laboratory Standards, 2008 and 2017). Several test tubes of sterile Luria-Bertani (LB) and Bacto casitone media were prepared for bacteria and yeast, respectively. Different dilutions of the tested extract, Penicillin $\mathrm{G}$ and Fluconazole $(0.025$ to $1 \mathrm{ml})$ with concentration ranged from $(0.15$ to 6 $\mathrm{mg} / \mathrm{ml}$ ) was added and then inoculated with $100 \mu \mathrm{l}$ of $0.5 \mathrm{McF}$ arland standard from the tested microbes. All test tubes were incubated at $37^{\circ} \mathrm{C}$ for $24 \mathrm{hr}$ and the optica density (OD) of microbial growth measured at $600 \mathrm{~nm}$. Similarly, controls were prepared sole of the extract. MIC was expressed as $\mathrm{mg} / \mathrm{ml}$ of the antimicrobial agent.

The minimum bactericidal concentration and minimum fungicida concentration

The minimum bactericidal concentration (MBC) and minimum fungicidal concentration (MFC) were detected by subculturing the tested dilutions that inhibited the growth of the tested microbes in the MIC assay. The concentration of $3 \mathrm{mg} / \mathrm{ml}$ and $6 \mathrm{mg} / \mathrm{ml}$ for $E$. coli, $1.5 \mathrm{gm} / \mathrm{ml}$ and $3 \mathrm{mg} / \mathrm{ml}$ for $S$. aureus, B. cereus and $C$. albicans were inoculated into a fresh extract-free solid medium of LB and Bacto casitone media for bacteria and yeast, respectively. The agar plates were incubated at $37^{\circ} \mathrm{C}$ for $24 \mathrm{hr}$. The dilution that produced no single bacterial colony on a solid medium was considered as $\mathrm{MBC}$ and the dilution that produced no single fungal colony on a solid medium was considered as MFC (Akinyemi et al., 2005)

\section{Preparation and characterization of nanoparticles}

According to de Moura et al. (2008) and Hasaneen et al. (2014), CSNPs were prepared by polymerization of meth-acrylic acid (MAA) in CS solution. About 0.2 $\mathrm{g}$ of CS were dissolved in $0.5 \%(\mathrm{v} / \mathrm{v})$ MAA aqueous solution, on a magnetic stirrer for about $12 \mathrm{hr}$. Then, $0.2 \mathrm{mmol}$ of potassium persulfate were added with continuous stirring at $70^{\circ} \mathrm{C}$ for $1 \mathrm{~h}$. until CSNPs formation. Finally, the solution was cooled in an ice bath to stop the reaction, centrifuged for $30 \mathrm{~min}$. at $4000 \mathrm{rpm}$ and discarded the supernatant while, the particles were re-suspended in water. The formation of CSNPs occurs through intramolecular linkages between amino groups of CS and polymethacrylic acid (PMAA) carboxyl groups. As a result of CSNPs preparation, the solution of CS in MAA changed from a clear to an opalescent suspension.

CaPNPs were prepared by adding $7.5 \mathrm{ml}$ of $\mathrm{CaCl}_{2}(12.5 \mathrm{mM})$ dropwise to $1 \mathrm{ml}$ of bovine serum albumin (BSA) solution $(1 \mathrm{mg} / \mathrm{ml})$ with continuous stirring followed by dropwise addition of $1.5 \mathrm{ml}$ of sodium citrate $(10 \mathrm{mM})$ and $7.5 \mathrm{ml}$ of $\mathrm{Na}_{2} \mathrm{HPO}_{4}$ (12.5 mM). The solution was stirred for $3 \mathrm{hr}$. The prepared suspension was centrifuged at $10000 \mathrm{rpm}$ for $20 \mathrm{~min}$. The pellet was washed three times with 0.1 $\mathrm{M}$ phosphate buffer ( $\mathrm{pH}$ 7.2) and re-suspended in $1 \mathrm{ml}$ of phosphate buffer (He et al., 2000; Joyappa et al., 2009).

For further analysis, the nanosolutions were centrifuged (10000 rpm for $15 \mathrm{~min}$ ) and washed with distilled water to remove excess solution, and then NPs powder was centrifuged and dried at $60^{\circ} \mathrm{C}$ for $24 \mathrm{hrs}$

Shape and size of CSNPs and CaPNPs were identified by using transmission electron microscopy (TEM) analyses (JEOL, JEM-2100, Japan). Zeta potential, a measure of the stability of the prepared NPs, was measured by using by Zeta Potential Analyser (Malvern Zetasizer Nano-ZS90, Malvern, UK). Zeta potentia of the prepared NPs either alone or after loading with the selected antimicrobial fraction was measured at $25^{\circ} \mathrm{C}$ in 12 Zeta runs and a clear dispersal Zeta cell. Data obtained were analysed using Malvern Zetasizer software.

\section{Preparation of nano-loading agents}

According to Yu et al. (2014) and Hasaneen et al. (2016), loading of the antimicrobial compounds on the surface of either CSNPs or CaPNPs was performed by adding $10 \mathrm{ml}$ of the antimicrobial extract to $20 \mathrm{mg}$ of each NPs and stirred for $6 \mathrm{hr}$ at room temperature.

The antimicrobial activity assay for the loaded nanoparticles with extracted compounds

About $100 \mu 1$ of the selected antimicrobial fraction, NPs, the selected antimicrobial fraction loaded on the NP and Penicillin G or Fluconazole at concentration 50 $\mu \mathrm{g} / \mathrm{ml}$ were added in $0.5 \mathrm{~mm}$ pore of the inoculated agar plates with the tested microorganisms. Inhibition zones were measured in $\mathrm{mm}$ after $24 \mathrm{~h}$ of the incubation at $37^{\circ} \mathrm{C}$

The fold area was determined the solo antimicrobial compound inhibition zones and combined with NPs according to the equation $\left(\mathrm{B}^{2}-\mathrm{A}^{2}\right) / \mathrm{A}^{2}, \mathrm{~A}$ and $\mathrm{B}$; inhibition zones for antimicrobial compound alone and combined with NPs, respectively (Birla et al., 2009).

\section{The releasability and stability of the compound/NPs}

The dissolvability of compound/NPs was tried in various solvents like water, ethanol, methanol, n-butyl liquor, dimethylformamide (DMF), $\left.\mathrm{CH}_{3}\right)_{2} \mathrm{CO}$, hexane and toluene. The Zeta normal size (Zavg) and poly dispersity file (PDI) were determined using the Malvern Zetasizer Nano-ZS90, Malvern, UK.

The dialysis method was used to examine compound/NPs releasability. $5 \mathrm{ml}$ of compound/NPs was put in dialysis tubes (Spectra/Por Biotech; cellulose ester; MWCO 100,000) and afterward sank in $200 \mathrm{~mL}$ of distilled water at $37^{\circ} \mathrm{C}$. The NPs concentration was estimated by the atomic spectrometer (PerkinElmer, PinAAcle-500, UK).

\section{Statistical analysis}

Experimental tests were recorded in triplicate. Results were performed in the form of mean values \pm standard deviation (SD). In addition, the results were analysed using SPSS version 18 with statistically significance $p$-value $=0.05$. Consequently, the standard error (SE) was detected. 


\section{RESULTS}

Optimization of the antimicrobial compounds production by $S$. rimosus isolate

S. rimosus was grown on starch-nitrate liquid medium for 3, 5, 7 and 9 days Cultures were filtered through filter paper-Whatman's No. 1 and the filtrates were tested against the pathogenic microbes. The results showed that the best incubation period for the production of antifungal and antibacterial was the third day (Table $1)$.

Table 1 Antimicrobial potential of $S$. rimosus filtrate at different incubation periods against the pathogenic microbes.

\begin{tabular}{lcccc}
\hline $\begin{array}{l}\text { Incubation } \\
\text { period } \\
\text { (Days) }\end{array}$ & $\begin{array}{c}\text { Z. cereus } \\
\text { ATCC6633 }\end{array}$ & $\begin{array}{c}\text { S. aureus } \\
\text { ATCC25923 }\end{array}$ & $\begin{array}{c}\text { E. coli } \\
\text { ATCC25922 }\end{array}$ & $\begin{array}{c}\text { C. albicans } \\
\text { ATCC1023 }\end{array}$ \\
\hline 3 & $24 \pm 0.06$ & $14 \pm 0.06$ & $12 \pm 0.03$ & $18.6 \pm 0.13$ \\
\hline 5 & $16 \pm 0.06$ & $13.6 \pm 0.03$ & $10.6 \pm 0.03$ & $10 \pm 0.06$ \\
\hline 7 & $11 \pm 0.10$ & $10 \pm 0.06$ & $9.3 \pm 0.03$ & $9.6 \pm 0.07$ \\
\hline 9 & $9 \pm 0$ & $9 \pm 0$ & $9 \pm 0$ & $9.3 \pm 0.19$ \\
\hline
\end{tabular}

The effect of $\mathrm{pH}$ was studied by growing $S$. rimosus on starch-nitrate liquid media at different $\mathrm{pH}$ values and for 3 days. The results indicated that the best $\mathrm{pH}$ for the antifungal and antibacterial production was at $\mathrm{pH} 7.0$ (Table 2).

Table 2 Antimicrobial potential of $S$. rimosus filtrate at different $\mathrm{pH}$ values against the pathogenic microbes.

\begin{tabular}{lcccc}
\hline \multirow{2}{*}{$\begin{array}{l}\text { pH } \\
\text { value }\end{array}$} & $\begin{array}{c}\text { Z. cereus } \\
\text { ATCC6633 }\end{array}$ & $\begin{array}{c}\text { S. } \text { aureus } \\
\text { ATCC25923 }\end{array}$ & $\begin{array}{c}\text { E. coli } \\
\text { ATCC25922 }\end{array}$ & $\begin{array}{c}\text { C. albicans } \\
\text { ATCC1023 }\end{array}$ \\
\hline 4 & $0 \pm 0$ & $0 \pm 0$ & $0 \pm 0$ & $0 \pm 0$ \\
\hline 5 & $11 \pm 0.03$ & $15.3 \pm 0$ & $10.3 \pm 0.03$ & $11 \pm 0$ \\
\hline 6 & $13.6 \pm 0.03$ & $16 \pm 0$ & $11.6 \pm 0.03$ & $10 \pm 0$ \\
\hline 7 & $26.3 \pm 0.03$ & $17.6 \pm 0.03$ & $15 \pm 0$ & $18.3 \pm 0.08$ \\
\hline 8 & $21.6 \pm 0.06$ & $14 \pm 0$ & $12 \pm 0$ & $13.6 \pm 0.08$ \\
\hline 9 & $18 \pm 0$ & $14.6 \pm 0.03$ & $12 \pm 0$ & $13.3 \pm 0.03$ \\
\hline 10 & $12.6 \pm 0.03$ & $11.6 \pm 0.03$ & $10 \pm 0$ & $12.3 \pm 0.03$ \\
\hline
\end{tabular}

Different temperatures were tested to determine the best temperature for production of antifungal and antibacterial metabolites by growing $S$. rimosus on starch-nitrate liquid medium, $\mathrm{pH} 7.0$ and incubated for 3 days. The optimum temperature was recorded at $30^{\circ} \mathrm{C}$. By increasing the temperature, the inhibition zone decreased as shown in Table 3.

Table 3 Antimicrobial potential of $S$. rimosus filtrate at different temperatures against the pathogenic microbes.

\begin{tabular}{lcccc}
\hline \multirow{2}{*}{$\begin{array}{l}\text { Temperature } \\
\left({ }^{\circ} \mathbf{C}\right)\end{array}$} & \multicolumn{4}{c}{ Zone of inhibition $(\mathbf{n}=\mathbf{3}, \mathbf{m m}$, mean $\pm \mathbf{S E})$} \\
\cline { 2 - 5 } & $\begin{array}{c}\text { B. cereus } \\
\text { ATCC6633 }\end{array}$ & $\begin{array}{c}\text { S. } \text { aureus } \\
\text { ATCC25923 }\end{array}$ & $\begin{array}{c}\text { E. coli } \\
\text { ATCC25922 }\end{array}$ & $\begin{array}{c}\text { C. } \text { albicans } \\
\text { ATCC1023 }\end{array}$ \\
\hline 20 & $0 \pm 0$ & $0 \pm 0$ & $0 \pm 0$ & $0 \pm 0$ \\
\hline 25 & $20.3 \pm 0.03$ & $16.3 \pm 0.03$ & $15 \pm 0.05$ & $13.6 \pm 0.06$ \\
\hline 30 & $23.6 \pm 0.01$ & $18 \pm 0$ & $15.3 \pm 0.05$ & $16.6 \pm 0.01$ \\
\hline 35 & $18.6 \pm 0.06$ & $14.6 \pm 0.06$ & $12.6 \pm 0.03$ & $15.6 \pm 0.03$ \\
\hline 40 & $12.3 \pm 0.03$ & $10.3 \pm 0.03$ & $11 \pm 0$ & $12.6 \pm 0.01$ \\
\hline
\end{tabular}

Different carbon sources test showed that the starch was the best carbon source for antimicrobial metabolites production followed by sucrose, glucose and lactose (Table 4).

Table 4 Antimicrobial potential of S. rimosus filtrate at different carbon sources against the pathogenic microbes.

\begin{tabular}{lcccc}
\hline \multirow{2}{*}{$\begin{array}{l}\text { Carbon } \\
\text { Source }\end{array}$} & $\begin{array}{c}\text { Z. cereus } \\
\text { ATCC6633 }\end{array}$ & $\begin{array}{c}\text { S. aureus } \\
\text { ATCC25923 }\end{array}$ & $\begin{array}{c}\text { E. coli } \\
\text { ATCC25922 }\end{array}$ & $\begin{array}{c}\text { C. albicans } \\
\text { ATCC1023 }\end{array}$ \\
\hline Starch & $21 \pm 0.06$ & $25 \pm 0.06$ & $17.3 \pm 0.03$ & $18.6 \pm 0.06$ \\
\hline Glucose & $13.6 \pm 0.06$ & $12 \pm 0$ & $10.6 \pm 0.03$ & $15 \pm 0$ \\
\hline Sucrose & $16.7 \pm 0.03$ & $21 \pm 0.06$ & $15.3 \pm 0.03$ & $15.3 \pm 0.06$ \\
\hline Lactose & $10.6 \pm 0.03$ & $11.3 \pm 0.03$ & $0 \pm 0$ & $0 \pm 0$ \\
\hline Cellulose & $0 \pm 0$ & $0 \pm 0$ & $0 \pm 0$ & $10 \pm 0$ \\
\hline Chitin & $10 \pm 0$ & $5.6 \pm 0.03$ & $0 \pm 0$ & $0 \pm 0$ \\
\hline Glycerol & $0 \pm 0$ & $0 \pm 0$ & $0 \pm 0$ & $0 \pm 0$ \\
\hline \multicolumn{5}{c}{}
\end{tabular}

Effect of different nitrogen sources experiment showed that $\mathrm{KNO}_{3}$ was the greatest nitrogen source for the production of antifungal and antibacterial compounds followed by peptone, $\mathrm{NaNO}_{3}$, beef extract and casein for Gram-positive bacteria while it was peptone followed by casein, beef extract and yeast extract for the Gram-negative E. coli. The optimum activity of $S$. rimosus filtrate was at using casein as nitrogen source followed by $\mathrm{KNO}_{3}$, peptone, beef extract, $\mathrm{NaNO}_{3}$ and yeast extract (Table 5).

Table 5 Antimicrobial potential of $S$. rimosus filtrate at different nitrogen sources against the pathogenic microbes.

\begin{tabular}{lcccc}
\hline \multirow{2}{*}{$\begin{array}{l}\text { Nitrogen } \\
\text { source }\end{array}$} & $\begin{array}{c}\text { Z. cereus } \\
\text { ATCC6633 }\end{array}$ & $\begin{array}{c}\text { S. aureus } \\
\text { ATCC25923 }\end{array}$ & $\begin{array}{c}\text { E. coli } \\
\text { ATCC25922 }\end{array}$ & $\begin{array}{c}\text { C. albicans } \\
\text { ATCC1023 }\end{array}$ \\
\hline $\mathrm{KNO}_{3}$ & $22 \pm 0.06$ & $16.6 \pm 0.03$ & $0 \pm 0$ & $13.6 \pm 0.03$ \\
\hline $\mathrm{NaNO}_{3}$ & $16.3 \pm 0.03$ & $12.3 \pm 0.03$ & $0 \pm 0$ & $10.3 \pm 0.03$ \\
\hline$\left(\mathrm{NH}_{4}\right)_{2} \mathrm{SO}_{4}$ & $0 \pm 0$ & $0 \pm 0$ & $0 \pm 0$ & $0 \pm 0$ \\
\hline Peptone & $17.6 \pm 0.03$ & $14.3 \pm 0.06$ & $16 \pm 0.06$ & $13.6 \pm 0.06$ \\
\hline Beef extract & $15.3 \pm 0.03$ & $12.3 \pm 0.03$ & $12.3 \pm 0.03$ & $12.6 \pm 0.03$ \\
\hline $\begin{array}{l}\text { Yeast } \\
\text { extract }\end{array}$ & $0 \pm 0.03$ & $13.3 \pm 0.03$ & $10.6 \pm 0.06$ & $10.3 \pm 0.03$ \\
\hline Casein & $14.6 \pm 0.06$ & $14.3 \pm 0.06$ & $12.4 \pm 0.03$ & $14.6 \pm 0.06$ \\
\hline
\end{tabular}

After the separation and extraction of crude metabolites using different organic solvents such as diethyl ether, petroleum ether, chloroform and butanol on the rotary evaporator, small, concentrated discs from each extract were prepared and tested against the pathogenic microbes. The best solvent for the extraction of antimicrobial compounds was diethyl ether as showed in Table 6.

Table 6 The best solvent for extraction of antimicrobial compounds.

\begin{tabular}{lcccc}
\hline \multirow{2}{*}{ Solvent } & \multicolumn{3}{c}{ Zone of inhibition $\mathbf{~} \mathbf{n}=\mathbf{3}, \mathbf{m m}$ mean \pm SE) } \\
\cline { 2 - 3 } & $\begin{array}{c}\text { B. cereus } \\
\text { ATCC6633 }\end{array}$ & $\begin{array}{c}\text { S. aureus } \\
\text { ATCC25923 }\end{array}$ & $\begin{array}{c}\text { E. coli } \\
\text { ATCC25922 }\end{array}$ & $\begin{array}{c}\text { C. albicans } \\
\text { ATCC1023 }\end{array}$ \\
\hline $\begin{array}{l}\text { Diethyl } \\
\text { ether }\end{array}$ & $18.3 \pm 0.06$ & $17 \pm 0$ & $11.3 \pm 0.06$ & $18 \pm 0$ \\
\hline $\begin{array}{l}\text { Petroleum } \\
\text { ether }\end{array}$ & $12 \pm 0$ & $12.6 \pm 0.06$ & $10 \pm 0$ & $13 \pm 0$ \\
\hline Chloroform & $10.6 \pm 0.03$ & $11.6 \pm 0.03$ & $9.3 \pm 0.03$ & $12 \pm 0$ \\
\hline Butanol & $11 \pm 0.06$ & $11.6 \pm 0.03$ & $11.6 \pm 0.03$ & $16 \pm 0.03$ \\
\hline
\end{tabular}

\section{Gas chromatography-mass analysis for the diethyl ether extract}

The components present in the extract of S. rimosus were identified by gas chromatography-mass (GC-MS). The chromatogram was showed in Figure 1. These components were arranged according to their active principles with their retention time (RT), percentage composition in the sample, molecular formula, and molecular weight (MW) was presented in Table 7. In this sample, nine antimicrobial components were identified and considered as organic acids as follow: 1,2-Benzenedicarboxylic acid, Dioctyl Ester (10.93\%) as the major component followed by 9- Octadecenoic acid (10.75\%), E,E,Z-1,3,12 Nonadecatriene-5,14-d Iol (9.42\%), 9-Hexadecenoic acid,9-octadecenyl ester, (Z,Z)- $(9.26 \%)$, Heptatriacotanol $(8.56 \%)$, Tributyl acetylcitrate $(8.18 \%)$, Z(13,14-Epoxy)tetradec-11-en-1-ol acetate (7.79\%), 1,3,5-Triaziene-2,4diamine,6-Chloro-N-Ethyl $(0.55 \%)$ and 1,4-Methanoazulene and Decahydro4,8,8-Trimethyl-9-Methylene- $(0.48 \%)$ (Figure 1$)$.

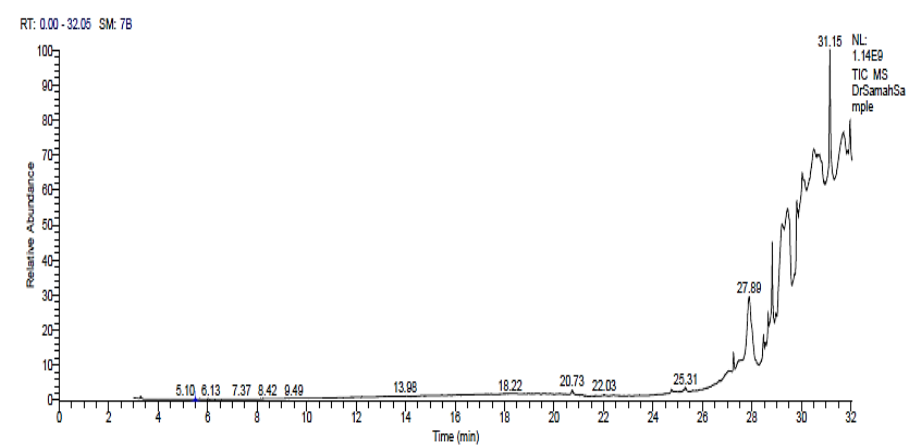

Figure 1 GC-MS chromatogram of the extracted diethyl ether filtrate of S. rimosus. 
Table 7 Components detected in the diethyl ether extraction of S. rimosus by GC-MS analysis

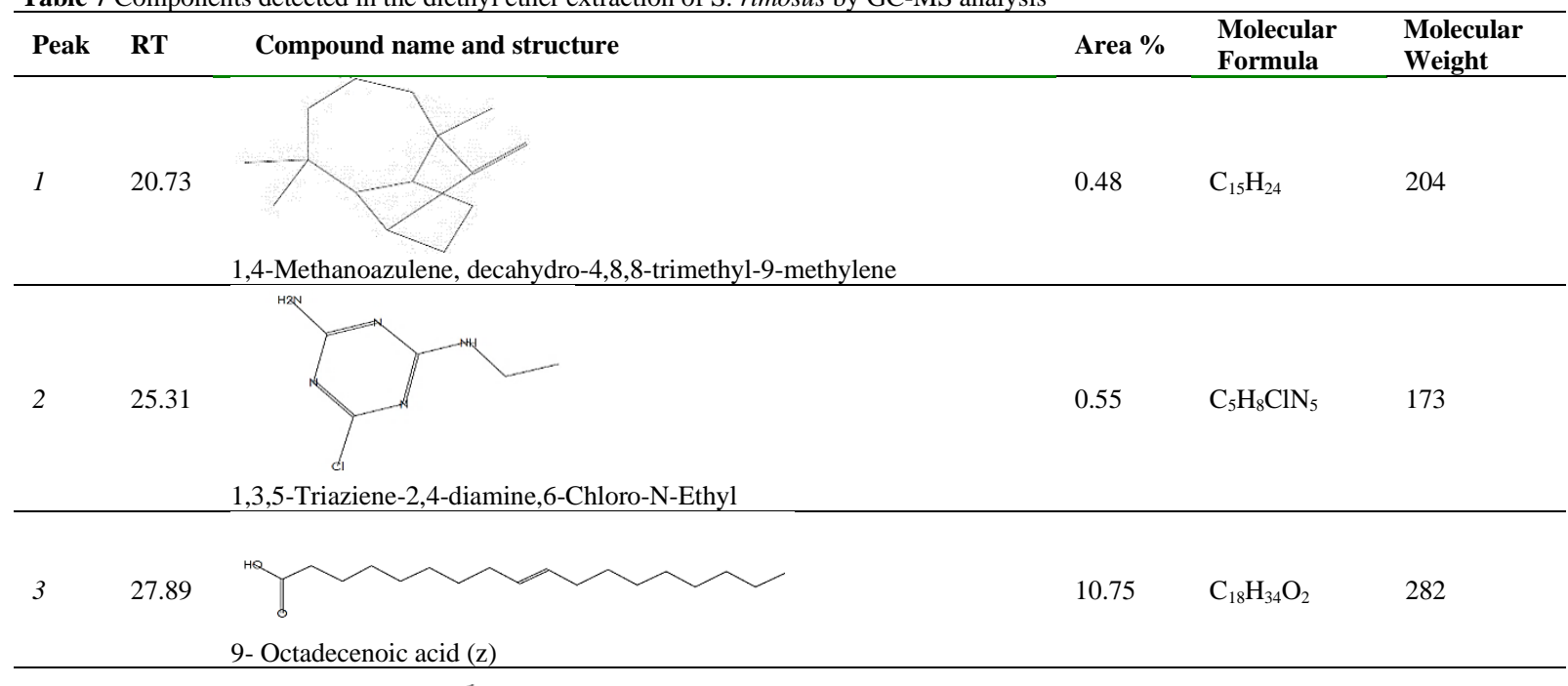

(1)

Charactarization of NPs and the loaded NPs on the antimicrobial compounds

CSNPs were appeared as spherical shaped NPs with a homogeneous size in distribution and diameter approximately $=22 \pm 2 \mathrm{~nm}$. The mean diameter of CSNPs was increased after loading with the antimicrobial compounds but still had a spherical shape with diameter ranged from 55 up to $100 \mathrm{~nm}$. (Figure 2A). CSNPs loaded with antimicrobial molecules diameter was approximately 55 upto $100 \mathrm{~nm}$ (Figure 2B)

CaPNPs had also a homogeneous spherical shape with a size diameter range from 70 to $95 \mathrm{~nm}$ (Figure 2C). Loading of antimicrobial compounds onto CaPNPs made them appeared in rod shape with width varying from 14 to $27 \mathrm{~nm}$ and length from 274 to $397 \mathrm{~nm}$ (Figure 2D).

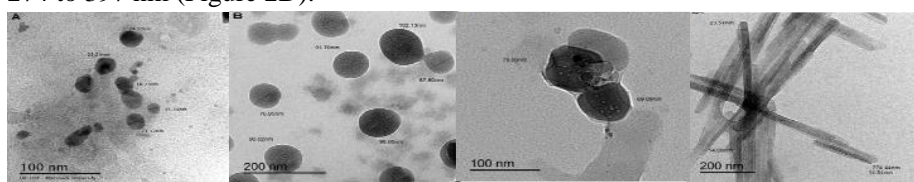

Figure 2 TEM micrograph of CSNPs; (A), CSNPs loaded with the antimicrobia compounds; (B), CaPNPs; (C) and CaPNPs loaded with the antimicrobial compounds; (D).
The values of Zeta potential stand for stability of NPs either alone or after loading them with the antimicrobial compounds (Table 8), where the more negative values can be considered as disability index of NPs preparation. Zeta Potential and electrical conductivity (EC) were increased by loading of the antimicrobial compounds on the NPs surfaces. The variation in the Zeta potential of the two NPs might be attributed to the difference in energy of electrical field in both CSNPs and CaPNPs surface surrounded by another ion.

Table 8 Zeta potential and EC of CSNPs and CaPNPs either alone or loaded with the antimicrobial compounds.

\begin{tabular}{lcc}
\hline Nanomaterial & Zeta potential & EC $(\mathbf{m S} / \mathbf{c m})$ \\
\hline CSNPs & $-7.48 \pm 0.19$ & $3.22 \pm 0.13$ \\
\hline Loaded CSNPs & $-7.93 \pm 0.03$ & $3.52 \pm 0.06$ \\
\hline CaPNPs & $-14.03 \pm 0.48$ & $1.62 \pm 0.07$ \\
\hline Loaded CaPNPs & $-22.87 \pm 1.92$ & $8.48 \pm 0.05$ \\
\hline
\end{tabular}

\section{Antimicrobial activity of S. rimosus diethyl ether extract}

The MIC of the diethyl ether extract of $S$. rimosus was $3 \mathrm{mg} / \mathrm{ml}$ for $E$. coli and 1.5 $\mathrm{mg} / \mathrm{ml}$ for $S$. aureus, B. cereus and C. albicans. The MBC values of diethyl ether 
extract of S. rimosus were $6.0 \mathrm{mg} / \mathrm{ml}$ for $E$. coli and $3.0 \mathrm{mg} / \mathrm{ml}$ for $S$. aureus and $B$. cereus. The MFC of $S$. rimosus extract against $C$. albicans was recorded at 3.0 $\mathrm{mg} / \mathrm{ml}$. While Penicillin G showed MIC value $6.25 \mathrm{mg} / \mathrm{ml}$ against $S$. aureus, $B$. cereus and E. coli. Fluconazole inhibited C. albicans at $1.5 \mathrm{mg} / \mathrm{ml}$.

\section{Antimicrobial activity of S. rimosus diethyl ether extract loaded on NPs}

The tested pathogenic microbes were resistant to the prepared NPs. On the other hand, the compound itself showed good activity which can be directly used for antimicrobial application but the loading process of the antimicrobial compounds on the synthesized NPs increased its activity (Table 9). This increasing occurred by the combination of the antimicrobial compound with NPs that increased fold areas especially against B. cereus, S. aureus and E. coli (Table 10). The less inhibition effects of antimicrobial compound $(13,13.3$ and $13.6 \mathrm{~mm})$ were against S. aureus, C. albicans and B. cereus, respectively. Conversely, the antimicrobial compound showed a good antimicrobial action when companied with NPs showing higher fold areas.

Table 9 Antimicrobial activity of S. rimosus extract after loading on the NPs.

\begin{tabular}{lcccc}
\hline \multirow{2}{*}{$\begin{array}{l}\text { Antimicrobial } \\
\text { agent }\end{array}$} & \multicolumn{4}{c}{ Zone of inhibition $(\mathbf{n}=\mathbf{3}, \mathbf{m m}$, mean \pm SE) } \\
\cline { 2 - 5 } & $\begin{array}{c}\text { B. cereus } \\
\text { ATCC6633 }\end{array}$ & $\begin{array}{c}\text { S. aureus } \\
\text { ATCC25923 }\end{array}$ & $\begin{array}{c}\text { E. coli } \\
\text { ATCC25922 }\end{array}$ & $\begin{array}{c}\text { C. albicans } \\
\text { ATCC1023 }\end{array}$ \\
\hline Extract & $14.0 \pm 0.03$ & $13.0 \pm 0.03$ & $13.6 \pm 0$ & $13.3 \pm 0$ \\
\hline CSNPs & ve- & ve- & ve- & ve- \\
\hline $\begin{array}{l}\text { CSNPs }+ \\
\text { extract }\end{array}$ & $17.5 \pm 0$ & $17.3 \pm 0.06$ & $22.2 \pm 0.03$ & $20.0 \pm 0$ \\
\hline CaPNPs & ve- & ve- & ve- & ve- \\
\hline $\begin{array}{l}\text { CaPNPs }+ \\
\text { extract }\end{array}$ & $16.5 \pm 0.03$ & $18.5 \pm 0.03$ & $25 \pm 0.03$ & $14.2 \pm 0$ \\
\hline Penicillin G & $30.2 \pm 0$ & $10.0 \pm 0.14$ & $12.0 \pm 0$ & - \\
\hline Fluconazole & - & - & - & $11.0 \pm 0.03$ \\
\hline
\end{tabular}

Table 10 Antimicrobial action of the companied antimicrobial compound with NPs.

\begin{tabular}{lccccc}
\hline Bacteria & \multicolumn{2}{c}{ Zone of inhibition $(\mathbf{n}=\mathbf{3}, \mathbf{m m}$, mean) } & \multicolumn{2}{c}{ Increase in fold area } \\
\cline { 2 - 6 } & $\begin{array}{c}\text { The } \\
\text { antimicrobial } \\
\text { compound } \\
(A)\end{array}$ & $\begin{array}{c}\text { CSNPs \& } \\
\text { compound } \\
(B)\end{array}$ & $\begin{array}{c}\text { CaPNPs } \\
\& \\
\text { compound } \\
\left(B^{\prime}\right)\end{array}$ & $\begin{array}{c}\text { CSNPs \& } \\
\text { compound } \\
(B)\end{array}$ & $\begin{array}{c}\text { CaPNPs } \\
\& \\
\text { compound } \\
\left(B^{\prime}\right)\end{array}$ \\
\hline E. coli & 14 & 17.5 & 16.5 & 0.56 & 0.39 \\
\hline $\begin{array}{l}S . \\
\text { aureus }\end{array}$ & 13 & 17.3 & 18.5 & 0.77 & 1.03 \\
\hline $\begin{array}{l}\text { B. } \\
\text { cereus }\end{array}$ & 13.6 & 22.2 & 25 & 1.66 & 2.38 \\
\hline $\begin{array}{l}C . \\
\text { albicans }\end{array}$ & 13.3 & 20 & 14.2 & 1.26 & 0.14 \\
\hline
\end{tabular}

- $\left(B^{2}\right.$ or $\left.B^{2}-A^{2}\right) / A^{2}$, where $\mathrm{A}$ and $\mathrm{B}$ or B' are the zones of inhibition for the antimicrobial compound and NPs \& compound, respectively.

\section{The releasability and stability of the compound/NPs}

The compound/NPs was stable in the several solvents for $3 \mathrm{~h}$. The compound/NPs showed a well diffusion in high polar solvents (ethanol and DMF) but low diffusion in nonpolar solvents (hexane and toluene). The dialysis experiments showed that the very slow diffusion rate of NPs (Figure 3). PDI and Zavg for compound/NPs were shown in Table 11.

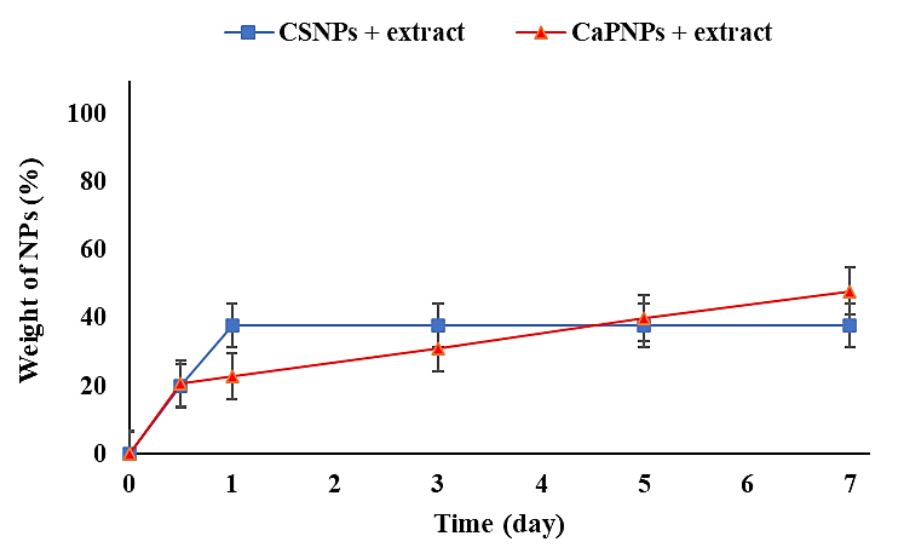

Figure 3 The release property of compound/NPs at $37^{\circ} \mathrm{C}$.
Table 11 The PDI and Zavg for compound/NPs in different solvents.

\begin{tabular}{lcccc}
\hline \multirow{2}{*}{ Solvent } & \multicolumn{2}{c}{ PDI (d.nm) } & \multicolumn{2}{c}{ Zavg (nm) } \\
\cline { 2 - 5 } & $\begin{array}{c}\text { CSNPs \& } \\
\text { compound }\end{array}$ & $\begin{array}{c}\text { CaPNPs \& } \\
\text { compound }\end{array}$ & $\begin{array}{c}\text { CSNPs \& } \\
\text { compound }\end{array}$ & $\begin{array}{c}\text { CaPNPs \& } \\
\text { compound }\end{array}$ \\
\hline Water & 0.421 & 0.332 & 324 & 233 \\
\hline Methanol & 0.8 & 0.7 & 850 & 742 \\
\hline Ethanol & 0.7 & 0.6 & 471 & 387 \\
\hline DMF & 0.5 & 0.4 & 397 & 277 \\
\hline n-butyl & 0.5 & 0.4 & 336 & 306 \\
alcohol & 0.8 & 0.7 & 1643 & 1522 \\
\hline Acetone & 0.9 & 0.8 & 1177 & 1007 \\
\hline Toluene & 0.6 & 0.5 & 632 & 595 \\
\hline Hexane & & & &
\end{tabular}

\section{DISCUSSION}

Actinomycetes are one of the most widely spread group of microbes in environment (Oskay et al., 2004). About $75 \%$ of the familiar traditional and therapeutically antibiotics are yielded by Streptomyces (Sujatha et al., 2005). On the other hand, several reports found that these microbes are obvious by the naked eye as colonies of about 1-10 mm in diameter (Groth et al., 1999). The majority of actinomycetes widely distributed in soil and the genus Streptomyces is the biggest producer of antibiotics. Streptomyces sp. had been well documented for industry applications for production of bioactive molecules for example vitamins, antibiotics, and enzymes (Laorpaksa et al., 1987).

Antimicrobial resistance is considered as a worrying problem for the public health and agriculture sectors especially strains such as E. coli, S. aureus, B. cereus and C. albicans (El-Zahed et al., 2021). So, new approaches should renovate to handling the resistance development. Recently, antimicrobial activity of nanomaterials such as CSNPs and CaPNPs had been developed as a response for this concern (Rao et al., 2020).

The capability of Streptomyces to produce the bioactive molecules is not a fixed ability nevertheless could be increased or lost by controlling nutrition conditions and cultivation (Saadoun and Gharaibeh, 2003). Improvement the growth and antibiotic assembly can be obtained by operating the nutritious and physical factors of the culturing settings, so the component of media shows a fundamental role in the productivity and financial side of the final progression. Changes in the some cultivation factors like incubation period, $\mathrm{pH}$, and temperature had a chief role in the production process (Kiranmayi et al., 2011). Furthermore, the change in carbon and nitrogen sources had reported to assume antibiotic production using Streptomyces (Barratt and Oliver, 1994; Reddy et al., 2011).

In this study, S. rimosus antimicrobial filtrate was selected, optimized, loaded on CSNPs and CaPNPs and then examined against bacteria and yeast. Different parameters were tested for obtaining the best conditions for the production of potent antimicrobial compounds. The present study showed that the best incubation time to produce antifungal and antibacterial compounds was the third day. Streptomyces BT-408 gave a maximum activity of its antimicrobial metabolite at the fourth day as recorded by Sujatha et al. (2005). Furthermore, Narayana and Vijayalakshmi (2008) observed that the production of antibiotic using Streptomyces albidoflavus started after the third day and reached maximum at the fifth day which represented as stationary phase of incubation period. It is known that the culture medium $\mathrm{pH}$ is the most significant factors, as it is an obvious effect on the enzyme's activity and their metabolic actions, in addition to the major influence on complex physiological occurrences such as cell morphology and membrane permeability (Guimarães et al., 2004). The results revealed that the best $\mathrm{pH}$ value for the production of strong antimicrobial compounds was at $\mathrm{pH} 7.0$ to $\mathrm{pH}$ 8.0. The neutral $\mathrm{pH}$ value was the most suitable for maximum assembly of metabolites (Ripa et al., 2009). On the other hand, the extreme pH is unsuitable for production of secondary metabolites. Neutral $\mathrm{pH}$ has main role in the growth of Streptomyces sp and production of secondary metabolite (Bhavana et al., 2014). Normally, Streptomyces are sensitive to temperature (Devi et al., 2015). The temperature is one of the most important factors which affect the growth of Streptomyces and production of bioactive compounds. After studying the effect of different temperatures on growth and bioactive metabolite production of $S$ rimosus, the results indicated that the best temperature for antimicrobial action was $30^{\circ} \mathrm{C}$. Extreme temperatures are generally inappropriate for the bioactive metabolite production as the harmful effect moved on the enzymes involved in the biosynthetic pathway (Ripa et al., 2009). Sugars and nitrogen play important roles as energy and structural compounds in cell. The cell metabolism of Streptomycetes at an excess nutritional led to the cell mass generation instead of secondary metabolites production. The tested S. rimosus showed maximum cell growth in medium amended with starch which considered a complex carbon source for Streptomyces as recorded by Huck et al. (1991). Starch and maltose used quickly to produce cellular components, so that; these carbon sources would be used as energy source for antibiotic production (AL-Mawlah, 2018). Glucose and lactose gave lowly production of bioactive metabolite, conversely it was found that cellulose and glycerol gave negative results and caused a catabolic repression. Starch was the best carbon source for the production of antibiotic (El-Naggar et 
al., 2003; Osman et al., 2011). Accordingly, the variance of carbon sources of media leads to variable levels of antimicrobial metabolite. Nitrogen source accommodating is the key factor in the regulation of antibiotic production in microorganisms (Voelker and Altaba, 2001). For investigating the effect of nitrogen source on the antimicrobial metabolite production from S. rimosus, different nitrogen sources were investigated. In comparison of some inorganic nitrogen sources and organic nitrogen sources it was found that potassium nitrate which considered inorganic nitrogen source was the optimum nitrogen source on bioactive metabolic production. Peptone has been found to favour antibiotic production as reported by Chattopadhyay and Sen (1997) and Praveen et al. (2008). Finally, results confirmed that the growth of $S$. rimosus was significantly affected by the type and nature of nitrogen source in the medium. The availability and nature of nitrogen from the inorganic and organic nitrogen compounds in fermentation media detected different effect on the antibiotic levels. High yields of antibacterial compounds are influenced by a low temporal coupling between antibacterial compounds synthesis and biomass accumulation.

The International Union of Pure and Applied Chemistry (IUPAC) recommend using the liquid-liquid dispersal over the conventional term solvent extraction (Rydberg, 1992). In this study, the crude extract was obtained by using four different solvents (diethyl ether, petroleum ether, chloroform, and butanol) respectively. The antimicrobial activity of diethyl ether fraction of the crude extract was most effect against $B$. cereus. The other solvents (petroleum ether, chloroform, and butanol) behaved lower antimicrobial activity. Diethyl ether is considered a good organic extracting solvent because it has a low polarity. Also, diethyl ether is used as an organic separator compound due to its natural material sources. Besides, diethyl ether is standard to anaesthesia in medical applications. In addition, diethyl ether is used as an organic solvent in many reactions (Butt et al., 1962).

Recently, GC-MS studies have been increased gradually for the analysis medical used components (Nandagopalan et al., 2015). In this study the GC-MS analysis showed multiple compounds from the diethyl ether extract from $S$. rimosus. These compounds are responsible for the anticandidal and antibacterial activity. Nine components were identified in the isolate of Streptomyces species. These compounds were 1,2-Benzenedicarboxylic acid, Dioctyl Ester (10.93\%) as the major component followed by 9- Octadecenoic acid (10.75\%), E,E,Z-1,3,12Nonadecatriene-5,14-d Iol (9.42\%), 9-Hexadecenoic acid,9-octadecenyl ester, (Z,Z)- (9.26\%), Heptatriacotanol (8.56\%), Tributyl acetylcitrate $(8.18 \%)$, Z(13,14-Epoxy)tetradec-11-en-1-ol acetate $\quad(7.79 \%), \quad$ 1,3,5-Triaziene-2,4diamine,6-Chloro-N-Ethyl $(0.55 \%)$ and 1,4-Methanoazulene,Decahydro-4,8,8Trimethyl-9-Methylene- $(0.48 \%)$. The biological activities of the components were identified according to the antimicrobial, antioxidant and antitumoral activities, beside that the nature of these compounds are mostly organic acids (Gálvez-Iriqui et al., 2019; Gopinath et al., 2020; Ulu et ak., 2021).

Adjuvants compounds play significant role in improving the effectiveness and immunogenicity of a drug in particular antibiotics and vaccines. Recently, the NPs research has paved away towards the development of improved and advanced antibiotics and vaccines. Adjuvants inorganic as well as organic compounds have recently been explored and exploited in NPs scale. They have been found to have great significance in entrapping and binding biomolecules of medical and veterinary importance and have proved to be more advantageous as compared to macromolecular forms in being inexpensive and easy to produce. Further, the bioavailability of the biomolecules has also been found to significantly increase when formulated in nano scale. Hence, those nanoparticles play major role in numerous fields like gene therapy, adjuvants and drug delivery systems (Joyappa et al., 2009). In this study, we have screened the probability to use CSNPs as delivery systems with antibiotic activity. CS is the second most abundant polymer in nature that found in invertebrates' structures and in the fungal cell walls (Duttagupta et al., 2015). CS is comprising of copolymers of $\beta-1,4$-linked $\mathrm{N}$ acetyl-D-glucosamine and D-glucosamine achieved by deacetylation of chitin. CSNPs showed a variable pattern release in the different stage. It includes that drug absorbing on the surface of NPs separated into the releasing medium rapidly, resulting in the burst release of drug in the initial stage. By degradation and diffusion, the drug moved through inside pores in NPs slowly and fell into the medium by diffusion. The formation of CSNPs occurs through intramolecular linkages between amino groups of CS and PMAA carboxyl groups which known as polymerization of MAA. After CSNPs preparation, the solution of CS in MAA changed from a clear to an opalescent suspension, this is due to formation of CSNPs with MAA. This compatible with the mechanism which made by De Vasconcelos et al. (2006). Lately, the antimicrobial activity of 1,2 Benzenedicarboxylic acid, dioctyl ester (BCA) had been described as S. griseus secondary metabolite and used in the biological control experiments (GálvezIriqui et al., 2019). In the present study, BCA was found as the major component of $S$. rimosus extract. The antimicrobial action of CS depends on chemical properties for example electrostatic interactions between the amino groups of CS and the stimulation of the destabilization of the plasma membrane (Chung and Chen, 2008; Xing et al., 2015). These mechanisms had been reported against bacteria, yeasts, and moulds (Teodoro et al., 2014; Chávez-Magdaleno et al. 2018). Yien et al. (2012) stated that $A$. niger was resistant to CSNPs. Similarly, our results revealed that CSNPs did not show any antimicrobial property but when combining with the extract efficiently showed stronger antimicrobial activity compared to the extract alone. The BCA antimicrobial activity mechanism has not been clarified.

CaPNPs are safe particles at the size of 50-100 nm (Joyappa et al., 2009). These NPs are beneficial for DNA mucosal immunity and vaccines (Mody et al., 2013; He et al., 2000), and show a good biocompatibility. Calcium phosphate nanoparticles (CAPs), potentially present in the most natural choice for antibiotic delivery platforms in bone therapy. Firstly, CaPNPs is the natural mineral component of bone in the form of crystals in bone, stiff but brittle, this is useful for imparting sufficient compressive strength to intrinsically tough collagen fibers. In addition, CaPNPs are a bioactive and osteo-conductive to bone growth. Not only that, but also it considered most bio-compatible nanomaterials assessed for toxicity (Singh and Lillard, 2009). CaPNPs were prepared by precipitation from aqueous solutions: flaky, brick-like, spherical and elongated orthogonal. CaPNPs are the most commonly used adjuvant and delivery system that was first developed by $\mathbf{H e}$ et al. (2002). The interaction between cells and particles utilized for drug delivery is critically depends on their chemical composition and other parameters like size, shape, surface, charge, crystallinity and porosity (Gratton, et al., 2008). CaPNPs are considered as hard material NPs, which have usually used in drug delivery (Xiang et al., 2021) and have thus been designed to stimulate antigen connection (Wendorf et al., 2006). Zeta Potential values of CSNPs and CaPNPs are considered as an important indicator for the stability of the two engineered nanomaterials. The variation in the ratio of Zeta potential can be attributed to the energy electrical field in both CSNPs and CaPNPs surface surrounded by another ion. The negative potential of the NPs loaded with the antimicrobial compounds approved the long-term stability and high dispersity.

The diethyl ether fraction had the broadest antimicrobial action in MIC, MBC and MFC against the pathogenic microbes. The extracted antibiotic showed antimicrobial spectrum against all the tested pathogenic microorganisms. Principally it is shown that the antimicrobial effect of NPs depends on its size and morphology, and this means that as size decreasing from $10 \mu \mathrm{m}$ to $10 \mathrm{~nm}$ as the surface area increased multifold, so the antimicrobial effect also increased multifold (Birla et al., 2009). In this work, compound/NPs was stable, with a slow releasement rate and a good dispersion of the solute in the solvent due to its smal PDI and Zavg (0-1). The solubility of compound/NPs were tested in different solvents (Danaei et al., 2018). In addition, the compound/NPs showed a good dispersion in DMF, water and n-butyl alcohol (PDI $<0.5$ d.nm, Zavg $<400 \mathrm{~nm}$ ). Also, the negative charge of the compound/NPs increased its dispersity and led to long-term stability preventing its aggregation.

The activity of this antibiotic was studied and matched with the results that reported by Rambali et al. (2001). Accordingly, we could conclude that the extracted compounds had abroad antimicrobial spectrum, and further study will be designed to elucidate the mode of action of the NPs loaded with the antimicrobial compounds as an antimicrobial agent.

\section{CONCLUSIONS}

Streptomyces rimosus crude antimicrobial metabolite was loaded on CSNPs and CaPNPs as a cost-effective and developed approach for antibiotics resistance problems. The crude antimicrobial metabolite included nine potent antimicrobial organic acids that confirmed using gas chromatography-mass. This method provides antimicrobial compounds that loaded on CSNPs and CaPNPs owning competitive size, shape and antimicrobial activities Thusly, S. rimosus could be developed as a nano-biofactory and drug delivery systems against human pathogenic microbes.

\section{REFERENCES}

Agnihotri, S. A., Mallikarjuna, N. N., \& Aminabhavi, T. M. (2004). Recent advances on chitosan-based micro-and nanoparticles in drug delivery. Journal of controlled release, 100(1), 5-28. https://doi.org/10.1016/j.jconrel.2004.08.010

Akinyemi, K. O., Oladapo, O., Okwara, C. E., Ibe, C. C., \& Fasure, K. A. (2005) Screening of crude extracts of six medicinal plants used in South-West Nigerian unorthodox medicine for anti-methicillin resistant Staphylococcus aureus activity. BMC complementary and alternative medicine, 5(1), 1-7. https://doi.org/10.1186/1472-6882-5-6

AL-Mawlah, Y. H. (2018). Antibacterial activity of Streptomyces sp. isolated from high tolerant ecosystem in Babylon Province, Iraq. Journal of university of Babylon for pure and applied sciences, 26(7), 303-308. https://www.journalofbabylon.com/index.php/JUBPAS/article/view/1505.

Babii, O., Wang, Z., Liu, G., Martinez, E. C., \& Chen, L. (2020). Low molecular weight chitosan nanoparticles for $\mathrm{CpG}$ oligodeoxynucleotides delivery: Impact of molecular weight, degree of deacetylation, and mannosylation on intracellular uptake and cytokine induction. International Journal of Biological Macromolecules, 159, 46-56. https://doi.org/10.1016/j.ijbiomac.2020.05.048

Baka, Z. A., Abou-Dobara, M. I., El-Sayed, A. K., \& El-Zahed, M. M (2020) Synthesis, characterization and antimicrobial activity of chitosan/Ag nanocomposite using Escherichia coli D8. Scientific journal for Damietta faculty of science 9(1): 1-6. https://dx.doi.org/10.21608/sjdfs.2019.194816 
Bakan, F. (2018). Gene delivery by hydroxyapatite and calcium phosphate nanoparticles: a review of novel and recent applications. HydroxyapatiteAdvances in Composite Nanomaterials, Biomedical Applications, and Its Technological Facets, 157-176. http://dx.doi.org/10.5772/intechopen.71062

Bakan, F. (2021). Production and characterization of antibiotic containing nano calcium phosphates. Nanotechnology Applications in Health and Environmental Sciences, 299-317. https://doi.org/10.1007/978-3-030-64410-9_16

Barratt, E. M., \& Oliver, S. G. (1994). The effects of nutrient limitation on the synthesis of stress proteins in Streptomyces lividans. Biotechnology letters, 16(12), 1231-1234. https://doi.org/10.1007/BF00149623

Beigoli, S., Hekmat, A., Farzanegan, F., \& Darroudi, M. (2021). Green synthesis of amorphous calcium phosphate nanopowders using Aloe Vera plant extract and assessment of their cytotoxicity and antimicrobial activities. Journal of Sol-Gel Science and Technology, 98(3), 508-516. https://doi.org/10.1007/s10971-021 05515-Z

Bhavana, M., Talluri, V. P., Kumar, K. S., \& Rajagopal, S. V. (2014). Optimization of culture conditions of Streptomyces carpaticus (mtcc-11062) for the production of antimicrobial compound. International journal of pharmacy and pharmaceutical sciences, $6(8)$

$281-5$

https://innovareacademics.in/journals/index.php/ijpps/article/view/2779.

Birla, S. S., Tiwari, V. V., Gade, A. K., Ingle, A. P., Yadav, A. P. \& Rai, M. (2009) Fabrication of silver nanoparticles by Phoma glomerata and its combined effect against Escherichia coli, Pseudomonas aeruginosa and Staphylococcus aureus Letters of Applied Microbiology, 48, 173-179. https://doi.org/10.1111/j.1472765X.2008.02510.X

Butt, J. B., Bliss, H., \& Walker, C. A. (1962). Rates of reaction in a recycling system-dehydration of ethanol and diethyl ether over alumina. AIChE Journal, 8(1), 42-47. https://doi.org/10.1002/aic.690080113

Campagnolo, L., Massimiani, M., Palmieri, G., Bernardini, R., Sacchetti, C., Bergamaschi, A., \& Pietroiusti, A. (2013). Biodistribution and toxicity of pegylated single wall carbon nanotubes in pregnant mice. Particle and fibre toxicology, 10(1), 1-13. https://doi.org/10.1186/1743-8977-10-21

Cano, A., Ettcheto, M., Espina, M., López-Machado, A., Cajal, Y., Rabanal, F., .. \& Souto, E. B. (2020). State-of-the-art polymeric nanoparticles as promising therapeutic tools against human bacterial infections. Journal of Nanobiotechnology, 18(1), 1-24. https://doi.org/10.1186/s12951-020-00714-2 Chattopadhyay, D., \& Sen, S. K. (1997). Optimisation of cultural conditions for antifungal antibiotic accumulation by Streptomyces rochei G164. Hindustan antibiotics bulletin, 39(1-4), 64-71. https://europepmc.org/article/med/10386018 Chávez-Magdaleno, M. E., Luque-Alcaraz, A. G., Gutiérrez-Martínez, P., CortezRocha, M. O., Burgos-Hernández, A., Lizardi-Mendoza, J., \& Plascencia-Jatomea M. (2018). Effect of chitosan-pepper tree (Schinus molle) essential oil biocomposites on the growth kinetics, viability and membrane integrity of Colletotrichum gloeosporioides. Revista Mexicana de Ingeniería Química, 17(1), 29-45. https://doi.org/10.24275/uam/izt/dcbi/revmexingquim/2018v17n1/Chavez Chung, Y. C., \& Chen, C. Y. (2008). Antibacterial characteristics and activity of acid-soluble chitosan. Bioresource technology, 99(8), 2806-2814. https://doi.org/10.1016/j.biortech.2007.06.044

Clinical Laboratory Standards document M100-S26. (2017). Performance standards for antimicrobial susceptibility testing: Approved standard- twentyseven Edition, Clinical and Laboratory Standards Institute, Wayne, Pennsylvania, USA.

Clinical Laboratory Standards document M27-A3. (2008). Reference method for broth dilution antifungal susceptibility testing of yeasts: Approved Standard-Third Edition, Clinical and Laboratory Standards Institute, Wayne, Pennsylvania, USA. Danaei, M., Dehghankhold, M., Ataei, S., Hasanzadeh Davarani, F., Javanmard R., Dokhani, A., ... \& Mozafari, M. R. (2018). Impact of particle size and polydispersity index on the clinical applications of lipidic nanocarrier systems Pharmaceutics, 10(2), 57. https://doi.org/10.3390/pharmaceutics10020057 de Moura, M. R., Aouada, F. A., \& Mattoso, L. H. (2008). Preparation of chitosan nanoparticles using methacrylic acid. Journal of colloid and interface science, 321(2), 477-483. https://doi.org/10.1016/j.jcis.2008.02.006

De Vasconcelos, C. L., Bezerril, D. P., Dos Santos, D. E. S., Dantas, D. T., Pereira M. R., \& Fonseca, J. L. C. (2006). Effect of molecular weight and ionic strength on the formation of polyelectrolyte complexes based on poly (methacrylic acid) and chitosan. Biomacromolecules, 7(4), 1245-1252. https://doi.org/10.1021/bm050963w

Devi, C. S., Saini, A., Rastogi, S., Naine, S. J., \& Mohanasrinivasan, V. (2015) Strain improvement and optimization studies for enhanced production of erythromycin in bagasse-based medium using Saccharopolyspora erythraea MTCC 1103. 3 Biotech, 5(1), 23-31. https://doi.org/10.1007/s13205-013-0186-5 Dorozhkin, S. V., \& Epple, M. (2002). Biological and medical significance of calcium phosphates. Angewandte chemie international edition, 41(17), 3130-3146. https://doi.org/10.1002/1521-3773(20020902)41:17<3130::AID-

ANIE3130>3.0.CO;2-1

Dudhani, A. R., \& Kosaraju, S. L. (2010). Bioadhesive chitosan nanoparticles: Preparation and characterization. Carbohydrate polymers, 81(2), 243-251. https://doi.org/10.1016/j.carbpol.2010.02.026
Duttagupta, D., M Jadhav, V., \& J Kadam, V. (2015). Chitosan: a propitious biopolymer for drug delivery. Current drug delivery, 12(4), 369-381. https://doi.org/10.2174/1567201812666150310151657

El-Naggar, M. Y., Hassan, M. A., Said, W. Y., \& Samy A, E. A. (2003). Effect of support materials on antibiotic MSW2000 production by immobilized Streptomyces violatus. The Journal of general and applied microbiology, 49(4), 235-243. https://doi.org/10.2323/jgam.49.235

El-Zahed, M. M., Baka, Z., Abou-Dobara, M. I., \& El-Sayed, A. (2021). In vitro biosynthesis and antimicrobial potential of biologically reduced graphene oxide/Ag nanocomposite at room temperature. Journal of microbiology, biotechnology and food sciences, 10(6), e3956-e3956 https://doi.org/10.15414/jmbfs.3956

Epple, M. and Baeuerlein, E. (2007): Biomineralisation: Medical and clinical aspects, Wiley-VCH, Weinheim. V (3): pp. 13 https://library.wur.nl/WebQuery/titel/2001725

Gálvez-Iriqui, A. C., Cortez-Rocha, M. O., Burgos-Hernández, A., CalderónSantoyo, M., Argüelles-Monal, W. M., \& Plascencia-Jatomea, M. (2019). Synthesis of chitosan biocomposites loaded with pyrrole-2-carboxylic acid and assessment of their antifungal activity against Aspergillus niger. Applied microbiology and biotechnology, 103(7), 2985-3000. https://doi.org/10.1007/s00253-019-09670-w

Goldschmidt, G. M., Krok-Borkowicz, M., Zybała, R., Pamuła, E., Telle, R. Conrads, G., \& Schickle, K. (2021). Biomimetic in situ precipitation of calcium phosphate containing silver nanoparticles on zirconia ceramic materials for surface functionalization in terms of antimicrobial and osteoconductive properties. Dental Materials, 37(1), 10-18. https://doi.org/10.1016/j.dental.2020.09.018

Goodfellow, M., Kampfer, P., Busse, H. J., Trujillo, M. E., Suzuki, K., Ludwig, W. and Whitman, W. B. (2012): Taxonomic outline of the phylum Actinobacteria. In: Bergey"es Manual of Systematic Bacteriology, 2nd edition. Eds: Whitman, W B. New York: Springer. pp. 29-31. https://doi.org/10.1007/978-0-387-68233-4_2 Gopinath, V., MubarakAli, D., Vadivelu, J., Kamath, S. M., Syed, A., \& Elgorban, A. M. (2020). Synthesis of biocompatible chitosan decorated silver nanoparticles biocomposites for enhanced antimicrobial and anticancer property. Process Biochemistry, 99, 348-356. https://doi.org/10.1016/j.procbio.2020.09.011

Gräfe, U., Reinhardt, G., Schade, W., Krebs, D., Eritt, I., Fleck, W. F., \& Heinrich, E. (1982). Isolation and structure of novel autoregulators from Streptomyces

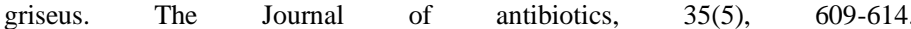
https://doi.org/10.7164/antibiotics.35.609

Gratton, S. E., Ropp, P. A., Pohlhaus, P. D., Luft, J. C., Madden, V. J., Napier, M E., \& DeSimone, J. M. (2008). The effect of particle design on cellular internalization pathways. Proceedings of the national academy of sciences, 105(33), 11613-11618. https://doi.org/10.1073/pnas.0801763105

Groth, I., Vettermann, R., Schuetze, B., Schumann, P., \& Sáiz-Jiménez, C. (1999) Actinomycetes in karstic caves of northern Spain (Altamira and Tito Bustillo). Journal of microbiological methods, 36(1-2), 115-122. https://doi.org/10.1016/S0167-7012(99)00016-0

Guimarães, L. M., de Araujo Furlan, R. L., Garrido, L. M., Ventura, A., Padilla, G., \& Facciotti, M. C. R. (2004). Effect of $\mathrm{pH}$ on the production of the antitumor antibiotic retamycin by Streptomyces olindensis. Biotechnology and applied biochemistry, 40(1), 107-111. https://doi.org/10.1042/BA20030166

Hamed, M. M., Abd El-Mobdy, M. A., Kamel, M. T., Mohamed, H. I., \& Bayoumi, A. E. (2019). Phytochemical and biological activities of two asteraceae plants Senecio vulgaris and Pluchea dioscoridis L. Pharmacology Online, 2, 101-121. https://doi.org/10.1055/s-0035-1565700

Hasaneen, M. N. A. G., Abdel-aziz, H. M. M., \& Omer, A. M. (2016). Effect of foliar application of engineered nanomaterials: carbon nanotubes NPK and chitosan nanoparticles NPK fertilizer on the growth of French bean plant.

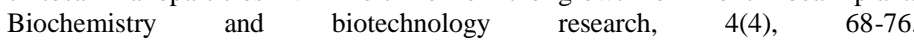
http://www.netjournals.org/z_BBR_16_021.html

Hasaneen, M. N. A., Abdel-Aziz, H. M. M., El-Bialy, D. M. A., \& Omer, A. M (2014). Preparation of chitosan nanoparticles for loading with NPK fertilizer African journal of biotechnology, 13(31). https://doi.org/10.5897/AJB2014.13699 He, Q., Mitchell, A. R., Johnson, S. L., Wagner-Bartak, C., Morcol, T., \& Bell, S. J. (2000). Calcium phosphate nanoparticle adjuvant. Clinical diagnostic laboratory Immunology, 7(6), 899-903. https://doi.org/10.1128/CDLI.7.6.899-903.2000

He, Q., Mitchell, A., Morcol, T., \& Bell, S. J. (2002). Calcium phosphate nanoparticles induce mucosal immunity and protection against herpes simplex virus type 2. Clinical and vaccine immunology, 9(5), 1021-1024. https://doi.org/10.1128/CDLI.9.5.1021-1024.2002

Hu, Y., Jiang, X., Ding, Y., Ge, H., Yuan, Y., \& Yang, C. (2002). Synthesis and characterization of chitosan-poly (acrylic acid) nanoparticles. Biomaterials 23(15), 3193-3201. https://doi.org/10.1016/S0142-9612(02)00071-6

Huck, T. A., Porter, N., \& Bushell, M. E. (1991). Positive selection of antibioticproducing soil isolates. Microbiology, 137(10), 2321-2329. https://doi.org/10.1099/00221287-137-10-2321

Hughes, G. A. (2005). Nanostructure-mediated drug delivery. Nanomedicine: nanotechnology, biology and medicine, 1(1), 22-30. https://doi.org/10.1016/j.nano.2004.11.009 
Janes, K. A., Calvo, P., \& Alonso, M. J. (2001). Polysaccharide colloidal particles as delivery systems for macromolecules. Advanced drug delivery reviews, 47(1), 83-97. https://doi.org/10.1016/S0169-409X(00)00123-X

Joel, E. L., \& Bhimba, B. V. (2012). Fungi from mangrove plants: their antimicrobial and anticancer potentials. International journal of pharmacy and pharmaceutical sciences,

4 ,

$139-142$ https://www.researchgate.net/publication/286279695_Fungi_from_mangrove_pla nts_Their_antimicrobial_and_anticancer_potentials

Joyappa, D. H., Kumar, C. A., Banumathi, N., Reddy, G. R., \& Suryanarayana, V. V. (2009). Calcium phosphate nanoparticle prepared with foot and mouth disease virus $\mathrm{P} 1-3 \mathrm{CD}$ gene construct protects mice and guinea pigs against the challenge virus. Veterinary microbiology, 139(1-2), 58-66. https://doi.org/10.1016/j.vetmic.2009.05.004

Kadian, S., Manik, G., Das, N., Nehra, P., Chauhan, R. P., \& Roy, P. (2020) Synthesis, characterization and investigation of synergistic antibacterial activity and cell viability of silver-sulfur doped graphene quantum dot (Ag@ S-GQDs) nanocomposites. Journal of Materials Chemistry B, 8(15), 3028-3037. https://doi.org/10.1039/C9TB02823D

Khalifehzadeh, R., \& Arami, H. (2020). Biodegradable calcium phosphate nanoparticles for cancer therapy. Advances in colloid and interface science, 279, 102157. https://doi.org/10.1016/j.cis.2020.102157

Kim, S. K., \& Rajapakse, N. (2005). Enzymatic production and biologica activities of chitosan oligosaccharides (COS): A review. Carbohydrate polymers, 62(4), 357-368. https://doi.org/10.1016/i.carbpol.2005.08.012

Kiranmayi, M. U., Sudhakar, P., Sreenivasulu, K., \& Vijayalakshmi, M. (2011). Optimization of culturing conditions for improved production of bioactive metabolites by Pseudonocardia sp. VUK-10. Mycobiology, 39(3), 174-181. https://doi.org/10.5941/MYCO.2011.39.3.174

Laorpaksa, S., Yingyong, A. and Thoongsuwan, S. (1987). Study of antibiotic producing actinomycetes from cave soil in central region of Thailand. Journal of national research council of Thailand, 19: 61-79. https://www.nrct.go.th/en\#

Małgorzata, P., Paweł, K., Iwona, M. L., Brzostek, T., \& Andrzej, P. (2020). Glutamatergic dysregulation in mood disorders: Opportunities for the discovery of novel drug targets. Expert Opinion on Therapeutic Targets, 24(12), 1187-1209. https://doi.org/10.1080/14728222.2020.1836160

Meade, E., Slattery, M. A., \& Garvey, M. (2021). Biocidal Resistance in Clinically Relevant Microbial Species: A Major Public Health Risk. Pathogens, 10(5), 598. https://doi.org/10.3390/pathogens10050598

Mody, K. T., Popat, A., Mahony, D., Cavallaro, A. S., Yu, C., \& Mitter, N. (2013) Mesoporous silica nanoparticles as antigen carriers and adjuvants for vaccine delivery. Nanoscale, 5(12), 5167-5179. https://doi.org/10.1039/C3NR00357D

Nandagopalan, V., Gritto, M. J., \& Doss, A. (2015). GC-MS analysis of bioactive components of the methanol extract of Hibiscus tiliaceus Linn. Asian journal of plant science and research, 5(3), 6-10. https://dx.doi.org/10.4103\%2F09748490.147223

Nandhini, S. U., Sudha, S., Jeslin, V. A., \& Manisha, S. (2018). Isolation, identification and extraction of antimicrobial compounds produced by Streptomyces sps from terrestrial soil. Biocatalysis and agricultural biotechnology, 15, 317-321. https://doi.org/10.1016/j.bcab.2018.06.024

Narayana, K. J. P., \& Vijayalakshmi, M. (2008). Production of extracellular protease by Streptomyces albidoflavus. Asian journal of biochemistry, 3(3), 198 202. https://dx.doi.org/10.3923/ajb.2008.198.202

Oskay, A. M., Üsame, T., \& Cem, A. (2004). Antibacterial activity of some actinomycetes isolated from farming soils of Turkey. African journal of Biotechnology, 3(9), 441-446. https://doi.org/10.5897/AJB2004.000-2087

Osman, M. E., Khattab, O. H., Zaghlol, G. M., \& El-Hameed, R. M. A. (2011) Optimization of some physical and chemical factors for lovastatin productivity by local strain of Aspergillus terreus. Australian journal of basic and applied Sciences, 5(6), 718-732. http://www.insipub.com/.../718-732.pdf

Praveen, V., Tripathi, C. K. M., Bihari, V., \& Srivastava, S. C. (2008). Production of actinomycin-D by the mutant of a new isolate of Streptomyces sindenensis. Brazilian journal of microbiology, 39, 689-692. https://doi.org/10.1590/S1517. 83822008000400017

Rambali, B., Fernandez, J. A., Van Nuffel, L., Woestenborghs, F., Baert, L. Massart, D. L., \& Odds, F. C. (2001). Susceptibility testing of pathogenic fung with itraconazole: a process analysis of test variables. Journal of antimicrobia chemotherapy, 48(2), 163-177. https://doi.org/10.1093/jac/48.2.163

Rao, S. S., Saptami, K., Venkatesan, J., \& Rekha, P. D. (2020). Microwaveassisted rapid synthesis of silver nanoparticles using fucoidan: Characterization with assessment of biocompatibility and antimicrobial activity. International journal of biological macromolecules, 163, 745-755 https://doi.org/10.1016/j.ijbiomac.2020.06.230

Reddy, N. G., Ramakrishna, D. P. N., \& Rajagopal, S. V. (2011). Optimization of culture conditions of Streptomyces rochei (MTCC 10109) for the production of antimicrobial metabolites. Egyptian journal of biology, 13, 21-29. https://doi.org/10.4314/ejb.v13i1.4

Ripa, F. A., Nikkon, F., Zaman, S. and Khondkar, P. (2009): Optimal conditions for antimicrobial metabolites production from a new Streptomyces sp. RUPA-
08PR isolated from Bangaladeshi soil. Mycobiolgy, 37(3): 211-214. https://doi.org/10.4489/MYCO.2009.37.3.211

Rydberg, J. (1992). Introduction to solvent extraction. In "Principles and practices of solvent extraction" eds: Rydberg,U., Musikas, C. and G. R. Choppin,G.R Dekker, New York. pp. 95. https://doi.org/10.1002/jctb.1219

Saadoun, I., \& Gharaibeh, R. (2003). The Streptomyces flora of Badia region of Jordan and its potential as a source of antibiotics active against antibiotic-resistant bacteria. Journal of arid environments, 53(3), 365-371. https://doi.org/10.1006/jare.2002.1043

Shackleton, C. H. (2008): Genetic disorders of steroid metabolism diagnosed my mass spectrometry, in: Blau, N. Duren, M. and Gibson, K. M. (Eds.), Laboratory guide to the methods in biochemical genetics, $1^{\text {st }}$ ed., Springer, Berlin Heidelberg. pp. 549-605. https://doi.org/10.1007/978-3-540-76698-8_26

Shackleton, C. H. L. and Marcos, P. G. M. (2006): Steroid profiling. In: diagnosis of disorders affecting steroid synthesis and metabolism. (Eds.): Gross, M. and Caprioli, R. The encyclopedia of mass spectrometry, Elsevier, Amsterdam. pp. 789-813. https://doi.org/10.1016/j.jsbmb.2010.04.010

Singh, R., \& Lillard Jr, J. W. (2009). Nanoparticle-based targeted drug delivery. Experimental and molecular pathology, 86(3), 215-223. https://doi.org/10.1016/j.yexmp.2008.12.004

Sujatha, P., Raju, K. B., \& Ramana, T. (2005). Studies on a new marine Streptomyces BT-408 producing polyketide antibiotic SBR-22 effective against methicillin resistant Staphylococcus aureus. Microbiological research, 160(2), 119-126. https://doi.org/10.1016/j.micres.2004.10.006

Teodoro, R. A. R., de Barros Fernandes, R. V., Botrel, D. A., Borges, S. V., \& de Souza, A. U. (2014). Characterization of microencapsulated rosemary essential oil and its antimicrobial effect on fresh dough. Food and Bioprocess Technology, 7(9), 2560-2569. https://doi.org/10.1007/s11947-014-1302-

Tsai, G. J., \& Su, W. H. (1999). Antibacterial activity of shrimp chitosan against Escherichia coli. Journal of food protection, 62(3), 239-243. https://doi.org/10.4315/0362-028X-62.3.239

Ulu, A., Birhanli, E., \& Ateș, B. (2021). Tunable and tough porous chitosan/ $\beta$ cyclodextrin/tannic acid biocomposite membrane with mechanic, antioxidant, and antimicrobial properties. International Journal of Biological Macromolecules. 188, 696-707. https://doi.org/10.1016/j.ijbiomac.2021.08.068

Voelker, F., \& Altaba, S. (2001). Nitrogen source governs the patterns of growth and pristinamycin production in 'Streptomyces pristinaespiralis'. Microbiology, 147(9), 2447-2459. https://doi.org/10.1099/00221287-147-9-2447

Wendorf, J., Singh, M., Chesko, J., Kazzaz, J., Soewanan, E., Ugozzoli, M., \& O'Hagan, D. (2006). A practical approach to the use of nanoparticles for vaccine delivery. Journal of pharmaceutical sciences, 95(12), 2738-2750 https://doi.org/10.1002/jps.20728

Wu, Q., Gao, H., Vriesekoop, F., Liu, Z., He, J., \& Liang, H. (2020). Calcium phosphate coated core-shell protein nanocarriers: Robust stability, controlled release and enhanced anticancer activity for curcumin delivery. Materials Science and Engineering: C, 115, 111094. https://doi.org/10.1016/j.msec.2020.111094

Xiang, C., Tenkumo, T., Ogawa, T., Kanda, Y., Nakamura, K., Shirato, M., ... \& Sasaki, K. (2021). Gene transfection achieved by utilizing antibacterial calcium phosphate nanoparticles for enhanced regenerative therapy. Acta Biomaterialia, 119, 375-389. https://doi.org/10.1016/j.actbio.2020.11.003

Xing, K., Zhu, X., Peng, X., \& Qin, S. (2015). Chitosan antimicrobial and eliciting properties for pest control in agriculture: a review. Agronomy for Sustainable Development, 35(2), 569-588. http://dx.doi.org/10.1007\%2Fs13593-014-0252-3 Yamamoto, H., Kuno, Y., Sugimoto, S., Takeuchi, H., \& Kawashima, Y. (2005). Surface-modified PLGA nanosphere with chitosan improved pulmonary delivery of calcitonin by mucoadhesion and opening of the intercellular tight junctions Journal of controlled Release, 102(2), 373-381. https://doi.org/10.1016/j.jconrel.2004.10.010

Yien, L., Zin, N. M., Sarwar, A., \& Katas, H. (2012). Antifungal activity of chitosan nanoparticles and correlation with their physical properties. International journal of Biomaterials, 632698. https://doi.org/10.1155/2012/632698

Yu, F., Ma, J., \& Han, S. (2014). Adsorption of tetracycline from aqueous solution onto multi-walled carbon nanotubes with different oxygen contents. Scientific reports, 4(1), 1-8. https://doi.org/10.1038/srep05326 